\title{
Tuning in to others: Exploring relational and collective bonding in singing and non-singing groups over time
}

Psychology of Music 2017, Vol. 45(4) 496-512 (C) The Author(s) 2016 Reprints and permissions: sagepub.co.uk/journalsPermissions.nav DOI: $10.1177 / 0305735616667543$ journals.sagepub.com/home/pom

@SAGE

\author{
Eiluned Pearce', Jacques Launay',2, Pádraig \\ MacCarron' and Robin I. M. Dunbar'
}

\begin{abstract}
Although it has been shown that singing together encourages faster social bonding to a group compared with other activities, it is unknown whether this group-level "collective" bonding is associated with differences in the ties formed between individual singers and individuals engaging in other activities ("relational" bonding). Here we present self-report questionnaire data collected at three time points over the course of seven months from weekly singing and non-singing (creative writing and crafts) adult education classes. We compare the proportion of classmates with whom participants were connected and the social network structure between the singing and non-singing classes. Both singers and creative writers show a steeper increase over time in relational bonding measured by social network density and the proportion of their classmates that they could name, felt connected with, and talked to during class compared to crafters, but only the singers show rapid collective bonding to the class-group as a whole. Together, these findings indicate that the process of creating a unitary social group does not necessarily rely on the creation of personal relationships between its individual members. We discuss these findings in the light of social cohesion theory and social identity theory.
\end{abstract}

\author{
Keywords \\ adult education, bonding, group dynamics, networks, social relationships
}

Mounting evidence suggests that singing facilitates social bonding (e.g. Clift \& Hancox, 2001; Grindley, Astbury, Sharples, \& Aguirre, 2011; Joseph \& Southcott, 2014; Pearce, Launay, \& Dunbar, 2015; Weinstein, Launay, Pearce, Dunbar, \& Stewart, 2015). However, it is becoming apparent that within the category of "social bonding", a distinction needs to be made between

\footnotetext{
${ }^{1}$ University of Oxford, Oxford, UK

${ }^{2}$ Brunel University, London, UK

\section{Corresponding author:}

Eiluned Pearce, Department of Experimental Psychology, University of Oxford, 9 South Parks Road, Oxford, OX1 3UD, UK.

Email: eiluned.pearce@psy.ox.ac.uk
} 
one-on-one engagement in dyadic interactions, for example with friends and family, and engagement with a wider social group, such as religious and activity groups. In other words, social connections can be either relational, whereby an individual can define themselves in terms of their personal relationships with specific others (partners, relatives, friends), or social connections can be collective: to a group or social category rather than to individual group members. Moreover, groups can be based on common identity, where members bond collectively to a shared social identity (social identity theory), or based on common bonds, where members form personal relationships with each other based on interpersonal attraction (social cohesion theory) and may secondarily develop a group identity to reflect this (Brewer \& Gardner, 1996; Hogg \& Turner, 1985; Hogg \& Williams, 2000; Prentice, Miller, \& Lightdale, 1994). Since both relational and collective bonding may play roles in promoting health and well-being (Haslam, Cruwys, \& Haslam, 2014; Kiecolt-Glaser \& Newton, 2001; Koball, Moiduddin, Henderson, Goesling, \& Besculides, 2010), behaviours and activities that can facilitate the development of personal relationships on the one hand, and collective identities on the other, could yield substantial public health benefits. In this article we examine whether different kinds of adult education classes can create relational and collective bonding over the course of seven months. In particular, we seek to establish whether the "social bonding" associated with singing can be relational as well as collective.

Building on previous literature, we recently demonstrated that singers in newly-formed choirs start to feel closer to their collective group significantly more quickly than individuals engaging in non-singing activities within a group context (creative writing and crafts), even though individuals involved in both musical and non-musical activities end up feeling similarly close after a seven-month period of weekly meetings (Pearce et al., 2015). These previous findings suggest that singing facilitates fast group-level (collective) bonding, but do not reveal how relationships change between individual group members over time. Indeed, the process of social network formation, in which relational bonds are built up with individual members of the group over time, has not, to our knowledge, been explicitly studied in singing groups before now. It is therefore unknown whether singing creates distinctly structured social networks compared to other group activities. For instance, due to the head start in group-level collective bonding associated with singing reported previously, singing could facilitate the formation of denser networks (with more members connected to one another) more quickly than other activities. If so, the proportion of connections that singers experience would increase more rapidly over time compared to non-singers. In the current paper, we use the same dataset from the study described above, but focus on relational bonding between individual classmates, rather than on the collective bonding to the group reported before.

In this article we combine multi-level modelling and structural network analysis (Wölfer, Faber, \& Hewstone, 2015) to explore whether the process of network formation over time differs between singers and non-singers, in line with the differing pattern of group-level bonding described previously (Pearce et al., 2015). In order to examine the effect of singing on the creation of ties between individual group members, a quasi-experimental approach was used, with data collection from weekly adult education classes ( 4 singing, 2 crafts, and 1 creative writing), set up for the purpose of the study by a UK adult education charity (the Workers' Educational Association, WEA), at three timepoints (months 1, 3, and 7) over the course of seven months. To look specifically at relational bonding, in this paper we look at how many of their classmates participants could name, talked to, and felt connected to (see also, Pearce, Launay, Machin, \& Dunbar, 2016). We test the hypotheses that (a) singers show a steeper increase in the proportion of classmates with whom they have social ties compared to non-singers, and (b) the 
structures of the social networks of the classes differ between singers and non-singers. Due to the differences between the craft and creative writing classes revealed by the network analysis, we also break down the comparisons by class activity, including a re-analysis of the group-level bonding data already published, comparing singers separately to creative writers and crafters. Crafts and creative writing classes were chosen as comparison activities because involvement in the creative arts in general seems to enhance social inclusion (Greaves \& Farbus, 2006; Newman, Curtis, \& Stephens, 2003), so comparing singing groups with other creative arts activities allowed us to explore whether singing is special in the way it facilitates social bonding, or whether all hobby activities bond people through the same processes. Moreover, crafts and creative writing are common activities in adult education, maximising the practical relevance of this research. In addition, we chose not to use physical activity classes (such as sport) as comparison conditions because high exertive activity has been shown to increase social bonding, and this might have masked any differential bonding effects linked to the synchrony associated with singing (Pearce, Launay, van Duijn, et al., 2016; Tarr, Launay, Cohen, \& Dunbar, 2015; Weinstein et al., 2015).

\section{Methods}

\section{Participants}

All participants gave full written informed consent at the start of the study and were debriefed at the end. As described elsewhere, the study included 84 singing participants (age: range $=$ $18-83$ years, $M=60, S D=12 ; 73$ female) and 51 non-singing participants (age: range $=24-$ 81 years, $M=52, S D=15 ; 45$ female) (Pearce et al., 2015). The majority of participants reported that their ethnicity was white (singing: 95\%, non-singing: 80\%). Attrition and nonattendance (e.g. due to illness or holidays) reduced the sample size of participants who had provided data at all three timepoints to 48 participants (57\%) in the singing condition and 27 participants (53\%) in the non-singing condition, but all participants are included and the statistical analysis used takes account of missing data.

\section{Tasks and materials}

The four singing classes were taught by professional tutors, using a Natural Voice Network style approach (http://www.naturalvoice.net/). The comparison condition comprised two craft classes and a creative writing class, which were also led by professional tutors. Each class lasted approximately two hours and took place during the day. The tutors had 2-20 years' experience of teaching their specialism.

All seven classes were set up specifically for the study: although some participants were known to each other as part of the local community, the class groups were newly formed at the start of the study. Similar proportions of participants knew at least one other person in their class prior to the start of the course in the two conditions (24 singers [30\%] reported knowing no one else before starting the class, number of others known $M=2$ others, range $=0-8$ other people; 14 non-singers [27\%] knew no one before starting the class, number of others known $M=2$ others, range $=0-5$ other people).

The classes ran weekly over seven months comprising two terms with a break in the middle. Data were collected at three timepoints, at month 1 (timepoint 1), month 3 (immediately prior to the break; timepoint 2), and month 7 (timepoint 3). ${ }^{1}$ At each of these three timepoints, participants completed a questionnaire that measured self-reported feelings of closeness to both 
their class as a whole (completed before and after the class) and towards their individual classmates (completed after the class).

\section{Questionnaire measures}

Bonding to individual classmates (relational bonding). Participants were first asked to list all the classmates whose names they could remember, then whether or not (dichotomous: yes or no) they felt connected to each of these individuals and finally whether or not they had talked to any of these individuals during the class. These items were taken to represent the extent to which a participant had a social tie with other members of their class.

Bonding to the group (collective bonding). Closeness to the class group as a whole was measured before and after the class using a modified version of the 7-point (1 to 7) pictorial Inclusion of Other in Self (IOS) scale (Aron, Aron, \& Smollan, 1992; Gächter, Starmer, \& Tufano, 2015), which replaced the "other" label with a label of "group". Participants were asked to "circle the diagram that best describes your current relationship to your class group as a whole". The series of paired circles that comprise the scale ranged from being completely non-overlapping to being almost completely overlapping. These were taken to represent how close or connected a participant felt to their class as a whole group, as opposed to individual class members. A similar analysis of these data has been previously published, comparing singing and non-singing participants (Pearce et al., 2015). In contrast, the re-analysis presented here compares singers separately to (i) creative writers and (ii) crafters (rather than combining these together to form a single comparison "non-singing" condition).

\section{Analysis and calculated variables}

Calculated variables for multi-level modelling. Proportions of classmates named, reported connected to, and reported talked to were calculated separately by dividing the number of names listed by the total number of individuals in the corresponding class (excluding the class tutor and anyone who was not identifiable as a research participant), in order to take account of differing class sizes (class sizes for singers: 23, 28, 16, and 17 individuals; for creative writers: 18 individuals; for crafters: 13 and 20 individuals, although not all members attended each class). Since Cronbach's $\alpha=0.915$, a summary "relationship index" was calculated as the mean of these three variables. This index can be interpreted as the proportion of classmates with whom each participant had a social tie. The histogram of this variable showed a disproportionately high frequency of participants with relationship indices close to zero and, although quantitatively similar results were found when these outliers were included, the residuals of the resulting models were nonnormal. Consequently, participants with a relationship index score $\leqslant 0.05$ were excluded from the relationship index analyses presented here. For each participant the difference between IOS scores before and after the class was calculated for each of the three timepoints.

To take account of the fact that participants were nested in different classes and therefore do not represent independent data-points, $R$ was used to run multi-level linear models (MLM, equivalent to a nested ANOVA) that included "Class" as an overarching layer. Model residuals did not differ significantly from normality and did not exhibit heteroscedasticity once participants with a relationship index score $\leqslant .05$ were excluded.

Network analysis. A network for each class-group at each timepoint was created using Python, where the sum of the social tie variables (whether or not one named the other, whether or not 
one felt connected to the other, and whether or not one reported that they talked to the other during the class, all coded dichotomously) for both individuals in a dyad represented the strength of each tie between two participants.

To compare the network structures between the conditions, two parameters were measured: the density and the clustering coefficient. The density of each class network was calculated as the number of links over the number of possible links between classmates at each timepoint. For a given participant, the clustering coefficient was calculated as the actual number of connections between all the classmates named by that participant, divided by the total number of possible connections between those named classmates. The mean clustering coefficient for the entire network of each class was then calculated (Watts \& Strogatz, 1998), which is the number of complete triads (when two named classmates also name each other), relative to the total number of potential triads in the network: whether a participant's friends also named each other.

A network with a density of 1 and a clustering coefficient of 1 indicates that everybody is connected to everybody else. Alternatively, a high clustering coefficient and a low density demonstrates that the network contains sub-groups that are sparsely connected with each other (Newman \& Park, 2003). It should be noted that the networks of the classes presented here are much smaller than the networks usually studied and in smaller networks it is easier for everyone to have ties with everyone else. Consequently, these networks are likely to have a correspondingly high density compared to the large networks generally analysed, even if there is sub-structuring within them.

In some cases two members of a class shared the same first name and could not be distinguished from each other. In order to maximise the sample of participants in the networks we did not remove these data, but instead estimated the error that this introduced into the network models. To do so, we bootstrapped the data by randomly assigning the tie to one of the individuals in the pool of participants with the same first name to create a "resolved" network, and repeated this process 100 times. We took the mean density and clustering coefficient of these 100 realisations to represent the density or the clustering coefficient and the standard deviation to represent the uncertainty in the network properties. However, when displaying images of the networks (Figure 4), just one of these realisations is used as a schematic.

\section{Results}

\section{Hypothesis I: Singers show a steeper increase in the proportion of classmates with whom they have social ties compared to non-singers}

Baseline. No significant differences were found in the relationship index at baseline (timepoint 1 ) between singers and non-singers: $p=.325$.

Change over time. Modelling the effect of timepoint (1, 2, or 3) and Condition (singing, nonsinging) on the relationship index showed a main effect of timepoint (time 2 versus baseline: $t(276)=2.194, p=.029$; timepoint 3 versus baseline: $t(276)=4.063, p<.0001$ ), with no main effect of Condition $(p=.510)$ : Table 1, Figure 1 . However, the interactions between timepoint and Condition were significant: singers showed a significantly steeper increase between baseline and both timepoint $2, t(276)=3.657, p=.0003$, and timepoint $3, t(276)=3.728$, $p=.0002$, compared to non-singers, Figure 1. In contrast, there was no significant difference between timepoints 2 and 3 ( $p=.056)$ and no interaction between the contrast between timepoints 2 and 3 and Condition $(p=.839)$. In summary, the relationship index significantly increased between timepoint 1 and timepoint 2, but not between timepoints 2 and 3, for both 
Table I. Descriptive statistics for the relationship index (with values less than .05 removed) for singers and non-singers at timepoints I, 2, and 3.

\begin{tabular}{|c|c|c|c|c|c|c|c|}
\hline & & \multicolumn{2}{|c|}{ Timepoint 1} & \multicolumn{2}{|c|}{ Timepoint 2} & \multicolumn{2}{|c|}{ Timepoint 3} \\
\hline & & $n$ & $M(S D)$ & $n$ & $M(S D)$ & $n$ & $M(S D)$ \\
\hline \multirow{2}{*}{$\begin{array}{l}\text { Relationship } \\
\text { index }\end{array}$} & Non-singers & 41 & $0.192(0.131)$ & 36 & $0.278(0.193)$ & 31 & $0.347(0.191)$ \\
\hline & Singers & 55 & $0.156(0.087)$ & 65 & $0.372(0.159)$ & 59 & $0.445(0.165)$ \\
\hline
\end{tabular}

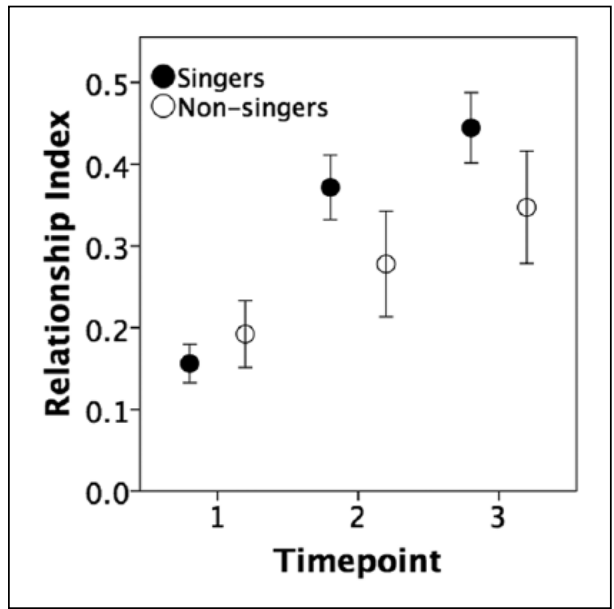

Figure I. Mean relationship index scores across the three timepoints for singers and non-singers, showing means \pm 2 SEs.

singers and non-singers, and did not differ between the two conditions. However, singers showed a significantly steeper increase in the relationship index between timepoints 1 and 2 compared to non-singers. This supports the hypothesis that singers show a more rapid increase in the proportion of classmates with whom they have social ties compared to non-singers.

\section{Hypothesis 2: The structure of the class social networks differs between singers and non-singers}

The changes in the network properties over time are shown in Figures 2 and 3. Figure 2 indicates that the singing classes generally demonstrate a rapid increase in network density after the first timepoint (change between timepoint 1 and timepoint 2 for each of the four classes: $0.44,0.24,0.46,0.21)$. In contrast, the craft classes show a much less rapid increase over time (change between timepoint 1 and timepoint 2 for each class: 0.14, 0.05), while the creative writing class falls within the variance of the singing classes and is therefore indistinguishable from them (change between timepoint 1 and timepoint 2: 0.30). These patterns mirror the relationship index results and indicate that creative writers and singers generally create relationships with a greater proportion of their classmates more quickly than do crafters. From timepoint 2 to timepoint 3 the change in density was similarly small in all three types of activity (singers: 0.18, 0.08, 0.08, 0.08; creative writers: 0.13; crafters: 0.04, 0.07). 


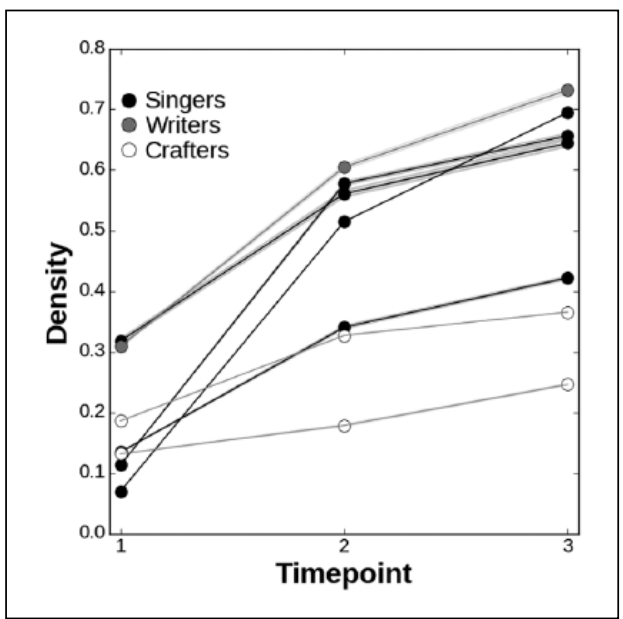

Figure 2. The cumulative change in the network density across the three timepoints for each of the singing, creative writing, and craft classes. The uncertainty in the data where participants share the same name is represented by the standard deviation of 100 bootstrapped samples, which is shown by the transparent shading.

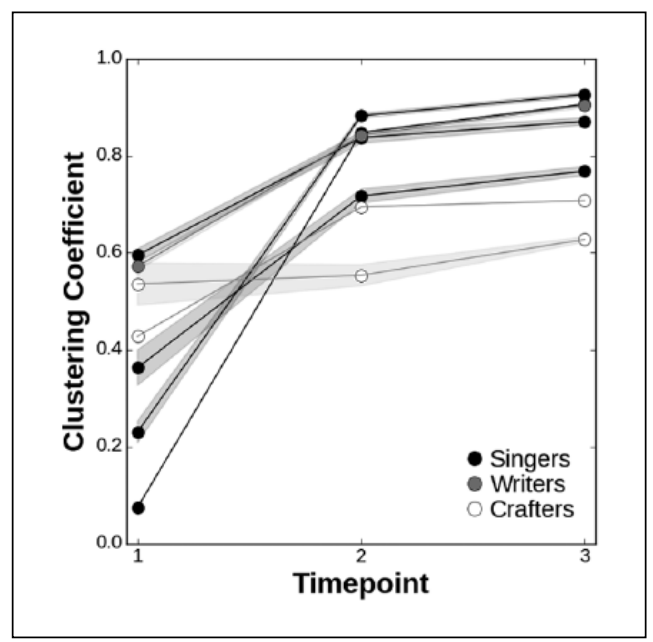

Figure 3. The cumulative change in the clustering coefficient across the three timepoints for each of the singing, creative writing, and craft classes. The transparent shading again represents the standard deviation due to the uncertainty in names.

The change in the clustering coefficient (Figure 3) between the first and second timepoints for most of the singing classes $(0.77,0.24,0.65$, and 0.35$)$ is particularly large when compared to each of the non-singing classes $(0.27,0.27$, and 0.02$)$, echoing the temporal patterns observed in network densities and the relationship index. Note that the singing class with the lowest change, and the creative writing class, both had comparatively high clustering coefficients at timepoint 1 . In terms of the actual values (rather than the change), the creative 


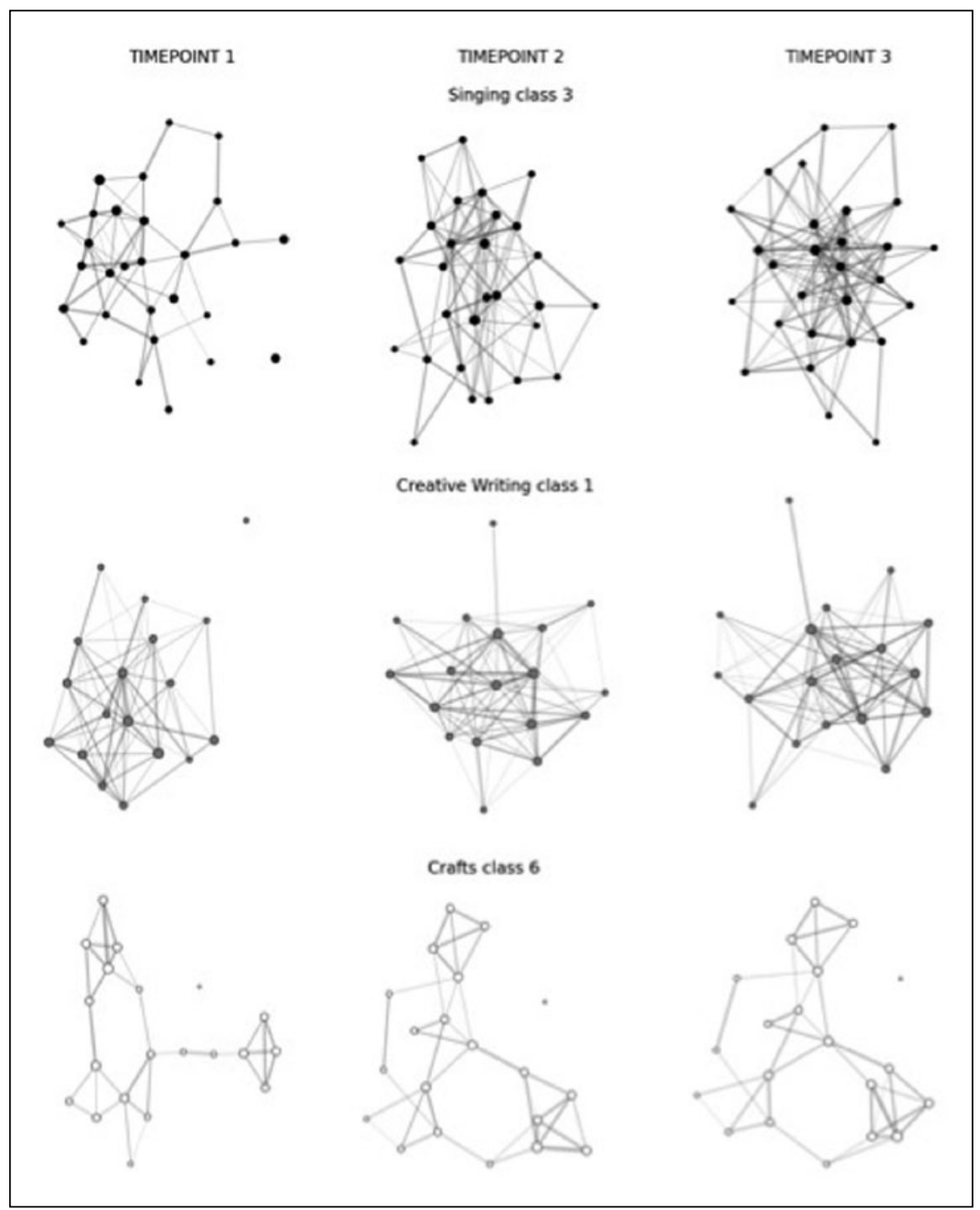

Figure 4. The networks for one of the singing classes, the creative writing class, and one of the craft classes at the three timepoints. The thickness of each link between classmates (represented by dots) is proportional to tie strength between the connected pairs. The size of the dots indicates the number of classmates to whom each participant is linked. The network layout as graphically displayed puts a distance between nodes (dots) by approximating the path distance between those nodes (Kamada \& Kawai, 1989). This can cause the network layout to change considerably as the network becomes more connected.

writing class is within the variance shown by the singing classes. The high clustering coefficients for the creative writing and singing classes suggest that the classmates named by a particular participant were also likely to be able to name each other.

As an illustration of the overall pattern of results, the social networks of one of the singing classes, the creative writing class, and one of the craft classes are shown in Figure 4. As the density and clustering coefficient parameters indicate, inspection of Figure 4 demonstrates that the connections between individuals in the craft class do not change as much as in the singing and creative writing classes, in which a greater proportion of all possible ties actually 
Table 2. Descriptive statistics for the relationship index (with values less than 0.05 removed) for singers, crafters, and writers at timepoints I, 2, and 3.

\begin{tabular}{|c|c|c|c|c|c|c|c|}
\hline & & \multicolumn{2}{|c|}{ Timepoint 1} & \multicolumn{2}{|c|}{ Timepoint 2} & \multicolumn{2}{|c|}{ Timepoint 3} \\
\hline & & $n$ & $M(S D)$ & $n$ & $M(S D)$ & $n$ & $M(S D)$ \\
\hline \multirow{3}{*}{$\begin{array}{l}\text { Relationship } \\
\text { index }\end{array}$} & Singers & 55 & $0.156(0.087)$ & 65 & $0.372(0.159)$ & 59 & $0.445(0.165)$ \\
\hline & Crafts & 27 & $0.154(0.116)$ & 20 & $0.183(0.114)$ & 16 & $0.225(0.107)$ \\
\hline & Creative writers & 14 & $0.266(0.129)$ & 16 & $0.397(0.208)$ & 15 & $0.478(0.175)$ \\
\hline
\end{tabular}

exist (higher density) and in which triads are more likely to be closed (higher clustering coefficient) compared to the craft class network.

Overall, these analyses support the hypothesis that the singing class networks have different structures (higher densities and clustering coefficients) compared to those of the craft classes. However, contrary to hypothesis 2, in terms of the parameters examined the structure of the creative writing class network is indistinguishable from those of the singing class networks (Figures 2 and 3).

\section{Comparing singers separately to crafters and creative writers}

Given that the social network analysis demonstrated similarities between the creative writing class and singing classes, we separated the creative writing class from the craft classes in order to determine whether the writing class exhibited any differences from the singing classes in terms of relationship index or group-bonding patterns when analysed alone.

Relationship index. No significant differences were found in the relationship index at baseline (timepoint 1$)$ between the singers and either crafters $(p=.641)$ or creative writers $(p=$ .239), who were also not significantly different from each other at baseline $(p=.417)$, Table 2 , Figure 5.

Relationship index scores (Table 2) increased between timepoint 1 and both timepoints 2 , $t(274)=8.621, p<.0001$, and 3, $t(274)=11.256, p<.0001$, independently of the course subject or the interactions between these two factors. No differences were found between singers and either crafters $(p=.821)$ or creative writers $(p=.193)$ independently of timepoint or interactions between time and course subject. Whereas no interaction effect between timepoint and the contrast between singers and creative writers was found (contrast between timepoint 1 and timepoint 2, $p=.130$, and timepoint 3, $p=.177$ ), significant interaction effects were found for the contrasts between crafters and singers with timepoint: crafters showed a significantly shallower increase in relationship index between timepoint 1 and both timepoint $2, t(274)=$ $-3.914, p=.0001$, and timepoint $3, t(274)=-4.242, p<.0001$, compared to singers. A significant interaction effect between course subject and timepoint was also found for comparisons between crafters and writers: writers showed a significantly steeper increase in relationship index between timepoint 1 and timepoint 3, $t(274)=2.043, p=.042$, but did not show an interaction for the contrast between timepoint 1 and $2(p=.117)$.

At timepoint 3, singers had significantly higher relationship index scores compared to crafters, $t(5)=3.116, p=.024$, but not compared to creative writers $(p=.666)$. Creative writers also demonstrated significantly higher relationship index scores at timepoint 3 compared to crafters: $t(4)=2.734, p=.046$. 


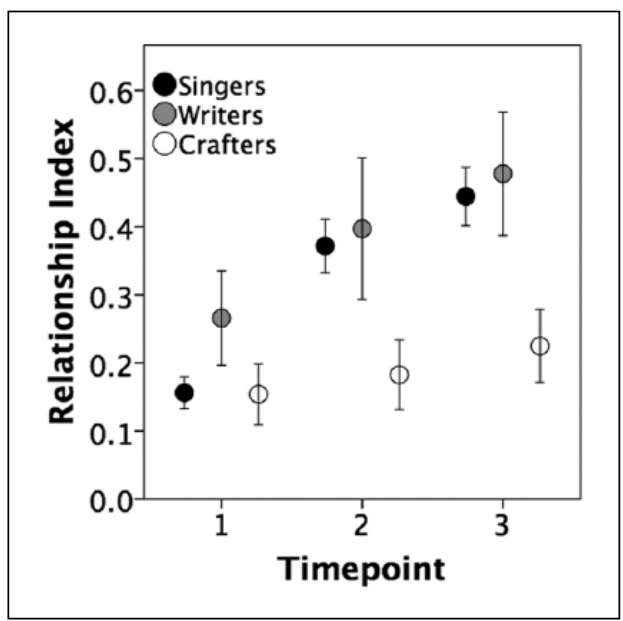

Figure 5. Mean relationship index scores across the three timepoints for singers, creative writers, and crafters, showing means \pm 2 SEs.

Together, these results suggest that in terms of creating relationships with individual classmates, creative writers show a similar pattern of results to singers and it is only the craft classes that show a shallower trajectory of increase and do not reach the same level of relational bonding with individual classmates compared to those engaged in the other activities.

Collective bonding to the group (IOS). To test the findings reported previously by the authors (Pearce et al., 2015) in the light of the difference uncovered here between the social networks of the creative writing and craft classes, we compared the change in IOS before and after class between singers, writers, and crafters. The increase in IOS scores during a class was significantly greater for singers than for both crafters, $t(297)=3.910, p=.0001$, and creative writers, $t(297)=3.992, p<.0001$, independently of timepoint. However, the two non-singing activities did not differ from each other $(p=.657)$. This suggests that singers show greater bonding to the class group as a whole, particularly at timepoint 1 (Figure 6), compared to nonsingers, whether the latter engaged in creative writing or crafts. Thus, although the relationship index demonstrated no differences in relational bonding between singers and creative writing, a difference did exist in collective bonding to the group as a whole.

\section{Relationship between relationship index and change in IOS}

Over all timepoints, change in IOS during a class was significantly negatively related to the relationship index for singers: $t(136)=-2.771, p=.006$ (model nested within timepoint and class), but not for crafters $(p=.433)$ or creative writers $(p=.866)$.

\section{Discussion}

Although singers did not demonstrate ties to a significantly higher proportion of their classmates than non-singers, singers did show a significantly steeper increase in the proportion of classmates they could name, felt connected to, and talked to during their class between timepoint 1 (baseline) and timepoint 2 . This was also reflected to some extent in the analysis of 


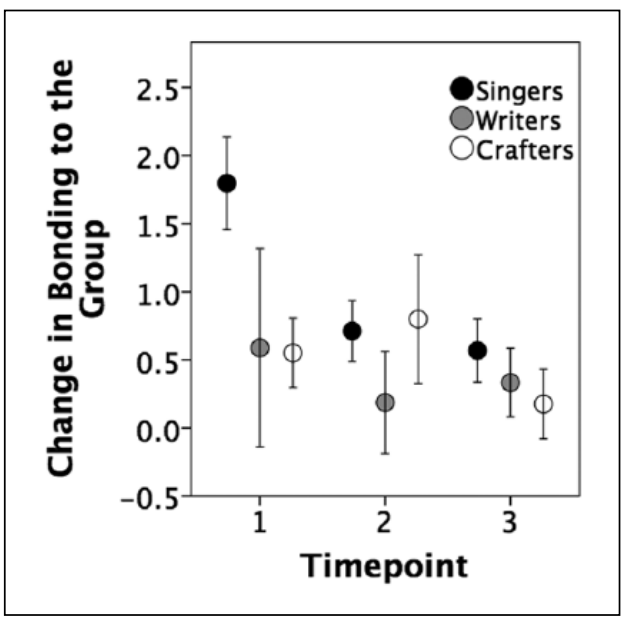

Figure 6. Mean change in bonding to the group (the difference in IOS scores after compared to before the class) across the three timepoints for singers, creative writers, and crafters, showing means \pm 2 SEs.

network structure, which indicated that singers showed a steep increase in network density between the first two timepoints. The hypothesis that the number of classmates with whom participants have social ties increases more rapidly for singers than non-singers (Hypothesis 1), was thus initially supported. However, this apparent difference between singers and non-singers seems to have been driven by differences between singers and crafters only. Examination of the structure of the social networks of the different classes revealed a discrepancy between the creative writers and the crafters, and this was supported by a more detailed analysis of the relationship index: whereas creative writers followed the same trajectory as singers, namely, a steep increase in network density and clustering between timepoints 1 and 2, indicating that all classmates tended to quickly form ties with everyone else in the group, the crafters did not seem to form as many connections with their classmates, but rather tended to know only a few others in the class. Hypothesis 2 is thus only partially supported: whereas singing classes do manifest differently structured networks compared to craft classes, the networks of the singing classes and the creative writing class were indistinguishable in the current study. Likewise, on closer inspection Hypothesis 1 is only supported with respect to the comparison between singers and crafters: creative writers show the same patterns as singers over time with respect to the proportion of classmates with whom they have ties.

In contrast to the similarity between singers and creative writers in terms of the speed of creating relational bonds and the relational structure of class networks, the increase in feelings of collective closeness to the group as a whole (rather than individual members) between the before- and after-class measures was significantly higher for singers compared to both creative writers and crafters, corroborating our previous conclusions. Consequently, although the social network structures and the pattern of rapid increase in numbers of connections to classmates were shared between singers and creative writers, there remains something special about singing in relation to fast collective bonding to the class as a single, non-individuated entity. These combined findings imply that, contra social cohesion theory, creating group-level social cohesion is not necessarily synonymous with establishing personal connections with individual group members: it is possible to feel a sense of group closeness without necessarily having personal relationships with others in the group (Castelli, Vanzetto, Sherman, \& Arcuri, 2001; 
Cialdini \& Goldstein, 2004; Goldstein, Cialdini, \& Griskevicius, 2008; Hogg \& Turner, 1985; Hogg \& Williams, 2000; Tafarodi, Kang, \& Milne, 2002).

Singing appears to lead to an immediate boost in closeness to the group even before group members have come to know each other individually, since the increase in closeness over the course of a class is much greater for singers than either of the comparison activities at timepoint 1 (see Figure 6). The finding that the fewer ties a participant has to group members, the greater the increase in closeness towards the collective group that person tends to experience after singing, corroborates work showing that after singing individuals feel a greater increase in closeness to a choir of less familiar individuals than they do to a choir with whom they are already connected (Weinstein et al., 2015). It could be that the shared intention, attention to and achievement of the collective goal of singing a piece of music (Launay, Dean, \& Bailes, 2013; Reddish, Fischer, \& Bulbulia, 2013; Shteynberg, Hirsh, Galinsky, \& Knight, 2014; Wolf, Launay, \& Dunbar, 2015), as well as the endorphin release associated with synchronous activity (e.g. Dunbar, Kaskatis, MacDonald, \& Barra, 2012; Pearce et al., 2015; Tarr et al., 2015; Tarr, Launay, \& Dunbar, 2014), lead group members to feel more positive towards each other. This in turn could boost connection to the group without the need for the prolonged history of social interaction usually required to create personal relationships (Pearce et al., 2015; Pearce, Launay, van Duijn, et al., 2016; Roberts \& Dunbar, 2011; Sutcliffe, Dunbar, Binder, \& Arrow, 2011). Like synchronous movement, the achievement of a "good sound" might be a strong marker of successful coordination and synchrony in a singing group producing a collective product, and this might create a positive feedback loop, making singers feel progressively more integrated into the group and more motivated to continue to cooperate (Lakens \& Stel, 2011; Launay, Dean, \& Bailes, 2014; Miles, Nind, \& Macrae, 2009; Páez, Rimé, Basabe, Wlodarczyk, \& Zumeta, 2015). Since the comparison classes did not involve collaborative projects or synchronous movement, this study cannot distinguish between the effects of the physical act of singing and those associated with working together towards a common goal. However, it seems likely that the combination of this sense of shared achievement and the "high" linked to endorphin release results in a greater feeling of closeness towards a relatively unfamiliar group of people. In addition, having singing in common may allow personal relationships between individual group members to develop more quickly than might usually be the case, because similarity is linked with increased liking and similarity in music taste is particularly predictive of social closeness between strangers (e.g. Launay \& Dunbar, 2015). The fact that relational bonds between singers developed in an environment of heightened collective closeness lends support to social identity theory, which predicts a top-down explanation of group formation, whereby individuals identify with the group and then develop interpersonal attraction based on this shared social identity (Hogg \& Williams, 2000).

Creative writers showed a rapid increase in the number of classmates they were connected to between timepoints 1 and 2, perhaps because the individual-project and small-group-work nature of these class activities allowed more discussion between classmates and this allowed interpersonal connections to develop. Furthermore, the often high level of intimacy and sharing of personal information associated with creative writing may have facilitated the development of closeness and trust between group members (Aron, Melinat, Aron, Vallone, \& Bator, 1997). Increase in closeness to the group as a whole occurred more gradually for the writers compared to the singers, and may have arisen through getting to know more people in the group via regular and repeated interaction and consequently feeling more integrated into the group as a whole. This process seems in line with social cohesion theory of group formation, where the group arises out of interpersonal attraction between individuals (Hogg \& Williams, 
2000; Lott \& Lott, 1965). It is possible that over time individuals began self-identifying as "writers" and this started to merge with their social identities as members of the writing group, perhaps adding to the salience of this identity status that did not arise for the singers and crafters (Brown, 2000; Gómez et al., 2011; Onorato \& Turner, 2004; Stets \& Burke, 2000; Swann, Jetten, Gomez, Whitehouse, \& Bastian, 2012). Unlike singing classes, in which the initial boost in group-level closeness seems to have kick-started the creation of bonds between classmates, the creative writers appear to have created personal ties that subsequently increased their feelings of integration into, and perhaps identification with, the group more gradually over time, yet equalled the group-level closeness of singers after seven months, as previously reported (Pearce et al., 2015).

Crafters did not seem to get to know their classmates individually, at least in terms of learning their names, to the same extent as those attending the other types of classes. Although, similarly to creative writers, crafters had more opportunity to talk to their classmates while working on individual-level projects compared to the singers, it could be that, unlike the writers, crafters were less likely to share personal information and this, combined with the absence of a strong collective ice-breaker effect, meant that the process of creating relational bonds with others in the class was slower compared to the writing and singing classes. Nonetheless, the crafters did reach the same level of closeness to the group as a whole as the other class-types and showed the same gradual increase as the writers. Part of this increase could be to do with familiarity: repeated exposure to the same people might have increased general liking even if the crafters did not learn each other's names (Kaptein, Nass, Parvinen, \& Markopoulos, 2013; Moreland \& Beach, 1992; Moreland \& Zajonc, 1982). As with both singing and writing, having something in common is likely to have increased attraction and liking of others in the class, and self-identification with it, even if an individual did not create social ties with all group members. Furthermore, the greater opportunities for conversation and the ensuing laughter may have enabled the collective bonding for writers and crafters that singing facilitated more quickly (Dunbar, Baron, et al., 2012; Pearce et al., 2015).

Overall, the different social bonding patterns demonstrated by singers, creative writers, and crafters indicate that feelings of closeness towards a group as a whole need not be synonymous with feelings of closeness towards individual members. Moreover, the different processes manifested by the singers and creative writers suggest that both social identity theory and social cohesion theory, respectively, can explain group formation in different contexts. A possible first step in teasing apart these potentially differing bonding processes could involve interviewing individuals who both sing and write in group contexts in order to gain insight into the bonding effects of different modes of activity, such as producing a collective product through synchronous singing versus creating individual products with intermittent chatting to neighbours.

Since both close interpersonal relationships and collective membership of a wider group seem to buffer individuals against physical and mental ill-health (Haslam et al., 2014; KiecoltGlaser \& Newton, 2001; Koball et al., 2010), all three creative arts activities examined here have the potential to improve well-being, at least if they are practised over seven months or more. However, given that singers showed both faster collective bonding and faster relational bonding, singing may generate well-being improvements more quickly than either creative writing or crafts, especially if the protective effects of relational and collective bonding are additive. Moreover, if crafters do not reach the same level of relational bonding as singers and creative writers, any effects of crafting on well-being might not be as strong as those associated with the other activities. Future work could address these questions. 


\section{Limitations}

One limitation of this work is that different numbers of participants and classes were involved in the different activities. Future work would benefit from having greater numbers of comparison craft and creative writing classes, to ensure that class networks are representative of groups engaged in a particular activity. Furthermore, it would be useful to compare singing classes with other activities that have a shared goal, such as drama, so as to explore whether fast collective bonding is a particular outcome of singing per se, or whether creating a collective product is the key factor.

In addition, as mentioned in the Methods, error was introduced into the network models due to multiple individuals sharing the same first name. Moreover, the procedure of collecting the network data relied upon classmates knowing each other's names, but having a social tie with someone does not necessarily require this knowledge. Although being able to name someone is a reasonable proxy for having a social relationship with them, future work could experiment with using other methods to elicit network information, for example having photos of each classmate in the questionnaire, if this was logistically feasible, and asking participants whether they felt connected to, or had talked to, each of their classmates, rather than just the ones they could name.

\section{Conclusion}

This study explored whether singing creates closer individual "relational" ties between group members more quickly than other activities and whether the structure of the resulting social networks differs between singing and non-singing groups. We demonstrate that singers end up knowing (in terms of being able to name them, feeling connected with them, and talking to them during class) a significantly greater proportion of their classmates than crafters, but not compared to creative writers. Consequently, in terms of relational bonding, singers and writers seem to follow a similar trajectory over time. In contrast, neither crafters nor creative writers show the fast "ice-breaker" effect demonstrated by singers of collective bonding to the group as a whole (as opposed to relational bonding to individual group members).

\section{Acknowledgements}

We thank Cole Robertson for helping to prepare the data for network analysis and all those who assisted with data collection: Rafael Wlodarski, Meg Hughes, Anna Machin, and Bronwyn Tarr. The adult education classes were funded and run by the Workers' Educational Association (WEA), including funding awarded to them by the Rayne Foundation. We are indebted to the WEA staff who organised the classes and in particular are very grateful to the learners and tutors who participated in the research, as well as Howard Croft and Cathie Zara from the WEA West Midlands region for their enthusiasm, hard work, and support. The authors declare no competing interests. Ethics approval for this study was provided by the Central University Research Ethics Committee (CUREC) of the University of Oxford (reference: MSD-IDREC-C1-2013-148).

\section{Funding}

The authors disclosed receipt of the following financial support for the research, authorship, and/or publication of this article: The research was funded by an ERC Advanced Investigator grant (295663) awarded to RD.

\section{Note}

1. The associated data can be found at http://ora.ox.ac.uk/objects/uuid:6ee38fae-1371-4744-b5e6$053 \mathrm{cc} 809 \mathrm{c} 201$. 


\section{References}

Aron, A., Aron, E. N., \& Smollan, D. (1992). Inclusion of other in the self scale and the structure of interpersonal closeness. Journal of Personality and Social Psychology, 63(4), 596-612. doi:10.1037/00223514.63.4.596

Aron, A., Melinat, E., Aron, E. N., Vallone, R. D., \& Bator, R. J. (1997). The experimental generation of interpersonal closeness: A procedure and some preliminary findings. Personality and Social Psychology Bulletin, 23(4), 363-377. doi:10.1177/0146167297234003

Brewer, M. B., \& Gardner, W. (1996). Who is this "we"? Levels of collective identity and self representations. Journal of Personality and Social Psychology, 71(1), 83-93. doi:10.1037/0022-3514.71.1.83

Brown, R. (2000). Social identity theory: Past achievements, current problems and future challenges. European Journal of Social Psychology, 30(6), 745-778. doi:10.1002/10990992(200011/12)30:6<745::AID-EJSP24>3.0.CO;2-O

Castelli, L., Vanzetto, K., Sherman, S. J. J., \& Arcuri, L. (2001). The explicit and implicit perception of ingroup members who use stereotypes: Blatant rejection but subtle conformity. Journal of Experimental Social Psychology, 37(5), 419-426. doi:10.1006/jesp.2000.1471

Cialdini, R. B., \& Goldstein, N. J. (2004). Social influence: Compliance and conformity. Annual Review of Psychology, 55(1974), 591-621. doi:10.1146/annurev.psych.55.090902.142015

Clift, S., \& Hancox, G. (2001). The perceived benefits of singing: Findings from preliminary surveys of a university college choral society. Journal of the Royal Society for the Promotion of Health, 121, 248-256.

Dunbar, R. I. M., Baron, R., Frangou, A., Pearce, E., van Leeuwin, E. J. C., Stow, J., ... van Vugt, M. (2012). Social laughter is correlated with an elevated pain threshold. Proceedings of the Royal Society B: Biological Sciences, 279(1731), 1161-1167.

Dunbar, R. I. M., Kaskatis, K., MacDonald, I., \& Barra, V. (2012). Performance of music elevates pain threshold and positive affect. Evolutionary Psychology, 10(4), 688-702.

Gächter, S., Starmer, C., \& Tufano, F. (2015). Measuring the closeness of relationships: A comprehensive evaluation of the "Inclusion of the Other in the Self" scale. PLOS ONE, 1O(6), e0129478. Retrieved from http://doi.org/10.1371/journal.pone.0129478

Goldstein, N. J., Cialdini, R. B., \& Griskevicius, V. (2008). A room with a viewpoint: Using social norms to motivate environmental conservation in hotels. Journal of Consumer Research, 35(3), 472-482. doi:10.1086/586910

Gómez, Á., Brooks, M. L., Buhrmester, M. D., Vázquez, A., Jetten, J., \& Swann, W. B., Jr. (2011). On the nature of identity fusion: Insights into the construct and a new measure. Journal of Personality and Social Psychology, 100(5), 918-933. doi:10.1037/a0022642

Greaves, C. J., \& Farbus, L. (2006). Effects of creative and social activity on the health and well-being of socially isolated older people: Outcomes from a multi-method observational study. The Journal of the Royal Society for the Promotion of Health, 126(3), 134-142. doi:10.1177/1466424006064303

Grindley, H., Astbury, J., Sharples, J., \& Aguirre, C. (2011). Benefits of group singing for community mental health and wellbeing: Survey \& literature review. Carlton, Australia: Victorian Health Promotion Foundation.

Haslam, C., Cruwys, T., \& Haslam, S. A. (2014). “The we's have it”: Evidence for the distinctive benefits of group engagement in enhancing cognitive health in aging. Social Science $\mathcal{E}$ Medicine, 120, 57-66. doi:10.1016/j.socscimed.2014.08.037

Hogg, M. A., \& Turner, J. C. (1985). Interpersonal attraction, social identification and psychological group formation. European Journal of Social Psychology, 15(1), 51-66. doi:10.1002/ejsp.2420150105

Hogg, M. A., \& Williams, K. D. (2000). From I to we: Social identity and the collective self. Group Dynamics: Theory, Research, and Practice, 4, 81-97. http://doi.org/10.1037/1089-2699.4.1.81

Joseph, D., \& Southcott, J. (2014). Singing and companionship in the Hawthorn University of the ThirdAge Choir, Australia. International Journal of Lifelong Education, 34(3), 334-347. doi:10.1080/0260 1370.2014 .991951

Kamada, T., \& Kawai, S. (1989). An algorithm for drawing general undirected graphs. Information Processing Letters, 31(1), 7-15. 
Kaptein, M., Nass, C., Parvinen, P., \& Markopoulos, P. (2013). Nice to know you: Familiarity and influence in social networks. In 2013 46th Hawaii International Conference on System Sciences (pp. 2745-2752). New York, NY: IEEE. doi:10.1109/HICSS.2013.418

Kiecolt-Glaser, J. K., \& Newton, T. L. (2001). Marriage and health: His and hers. Psychological Bulletin, 127(4), 472-503. doi:10.1037/0033-2909.127.4.472

Koball, H. L., Moiduddin, E., Henderson, J., Goesling, B., \& Besculides, M. (2010). What do we know about the link between marriage and health? Journal of Family Issues, 31(8), 1019-1040. doi:10.1177/ $0192513 X 10365834$

Lakens, D., \& Stel, M. (2011). If they move in sync, they must feel in sync: Movement synchrony leads to attributions of rapport and entitativity. Social Cognition, 29(1), 1-14. doi:10.1521/soco.2011.29.1.1

Launay, J., Dean, R. T., \& Bailes, F. (2013). Synchronization can influence trust following virtual interaction. Experimental Psychology, 60(1), 53-63. doi:10.1027/1618-3169/a000173

Launay, J., Dean, R. T., \& Bailes, F. (2014). Synchronising movements with the sounds of virtual partner enhances partner likeability. Cognitive Processing, 15(4), 491-501. doi:10.1007/s10339-0140618-0

Launay, J., \& Dunbar, R. I. M. (2015). Playing with strangers: Which shared traits attract us most to new people? PLoS ONE, 1O(6), e0129688. Retrieved from http://doi.org/10.1371/journal. pone.0129688

Lott, A. J., \& Lott, B. E. (1965). Group cohesiveness as interpersonal attraction: A review of relationships with antecedent and consequent variables. Psychological Bulletin, 64(4), 259-309. doi:10.1037/ h0022386

Miles, L. K., Nind, L. K., \& Macrae, C. N. (2009). The rhythm of rapport: Interpersonal synchrony and social perception. Journal of Experimental Social Psychology, 45(3), 585-589. doi:10.1016/j. jesp.2009.02.002

Moreland, R. L., \& Beach, S. R. (1992). Exposure effects in the classroom: The development of affinity among students. Journal of Experimental Social Psychology, 28(3), 255-276. doi:10.1016/ 0022-1031(92)90055-O

Moreland, R. L., \& Zajonc, R. B. (1982). Exposure effects in person perception: Familiarity, similarity, and attraction. Journal of Experimental Social Psychology, 18(5), 395-415. doi:10.1016/00221031(82)90062-2

Newman, M., \& Park, J. (2003). Why social networks are different from other types of networks. Physical Review E, 68(3), 36122.

Newman, T., Curtis, K., \& Stephens, J. (2003). Do community-based arts projects result in social gains? A review of literature. Community Development Journal, 38(4), 310-322. doi:10.1093/cdj/38.4.310

Onorato, R., \& Turner, J. (2004). Fluidity in the self concept: The shift from personal to social identity. European Journal of Social Psychology, 34(3), 257-278. Retrieved from http://doi.org/10.1002/ ejsp. 195

Páez, D., Rimé, B., Basabe, N., Wlodarczyk, A., \& Zumeta, L. (2015). Psychosocial effects of perceived emotional synchrony in collective gatherings, Journal of Personality and Social Psychology, 108(5), 711-729. doi:10.1037/pspi0000014

Pearce, E., Launay, J., \& Dunbar, R. I. M. (2015). The ice-breaker effect: Singing mediates fast social bonding. Royal Society Open Science, 2, 150221. Retrieved from http://doi.org/http://dx.doi.org/10.1098/ rsos. 150221

Pearce, E., Launay, J., Machin, A., \& Dunbar, R. I. M. (2016). Is group singing special? Health, well-being and social bonds in community-based adult education classes. Journal of Community \& Applied Social Psychology. Advance online publication. doi:10.1002/casp.2278

Pearce, E., Launay, J., van Duijn, M., Rotkirch, A., David-Barrett, T., \& Dunbar, R. I. M. (2016). Singing together or apart: The effect of competitive and cooperative singing on social bonding within and between sub-groups of a university Fraternity. Psychology of Music. Advance online publication. doi:10.1177/0305735616636208

Prentice, D. A., Miller, D. T., \& Lightdale, J. R. (1994). Asymmetries in attachments to groups and to their members: Distinguishing between common-identity and common-bond groups. In J. M. Levine \& R. L. Moreland (Eds.), Small groups: Key readings (pp. 83-95). Hove, UK: Psychology Press. 
Reddish, P., Fischer, R., \& Bulbulia, J. (2013). Let's dance together: Synchrony, shared intentionality and cooperation. PLoS ONE, 8(8), e71182.

Roberts, S., \& Dunbar, R. I. M. (2011). The costs of family and friends: An 18-month longitudinal study of relationship maintenance and decay. Evolution and Human Behavior, 32(3), 186-197. doi:10.1016/j. evolhumbehav.2010.08.005

Shteynberg, G., Hirsh, J. B., Galinsky, A. D., \& Knight, A. P. (2014). Shared attention increases mood infusion. Journal of Experimental Psychology: General, 143(1), 123-130. doi:10.1037/a0031549

Stets, J. E., \& Burke, P. J. (2000). Identity theory and social identity theory. Social Psychology Quarterly, 63(3), 224-237.

Sutcliffe, A., Dunbar, R. I. M., Binder, J., \& Arrow, H. (2011). Relationships and the social brain: Integrating psychological and evolutionary perspectives. British Journal of Psychology, 103, 149168. doi:10.1111/j.2044-8295.2011.02061.x

Swann, W. B. J., Jetten, J., Gomez, A., Whitehouse, H., \& Bastian, B. (2012). When group membership gets personal: A theory of identity fusion. Psychological Review, 119(3), 441-456. doi:10.1037/ a0028589

Tafarodi, R. W. R., Kang, S. S.-J., \& Milne, A. B. (2002). When different becomes similar: Compensatory conformity in bicultural visible minorities. Personality and Social Psychology Bulletin, 28(8), 11311142. doi:10.1177/01461672022811011

Tarr, B., Launay, J., Cohen, E., \& Dunbar, R. I. M. (2015). Synchrony and exertion during dance independently raise pain threshold and encourage social bonding. Biology Letters, 11(10). Retrieved from http://dx.doi.org/10.1098/rsbl.2015.0767

Tarr, B., Launay, J., \& Dunbar, R. I. M. (2014). Music and social bonding: "Self-other" merging and neurohormonal mechanisms. Frontiers in Psychology, 5, 1096. Retrieved from http://doi.org/ doi:10.3389/fpsyg.2014.01096

Watts, D. J., \& Strogatz, S. H. (1998). Collective dynamics of "small-world" networks. Nature, 393(6684), 440-442. doi:10.1038/30918

Weinstein, D., Launay, J., Pearce, E., Dunbar, R. I. M., \& Stewart, L. (2015). Singing and social bonding: Changes in connectivity and pain threshold as a function of group size. Evolution $\mathcal{E}$ Human Behaviour, 37(2), 152-158. doi:10.1016/j.evolhumbehav.2015.10.002

Wolf, W., Launay, J., \& Dunbar, R. I. M. (2015). Joint attention, shared motivation and social bonding. British Journal of Psychology, 107(2), 322-337. doi:10.1111/bjop.12144

Wölfer, R., Faber, N. S., \& Hewstone, M. (2015). Social network analysis in the science of groups: Crosssectional and longitudinal applications for studying intra- and intergroup behavior. Group Dynamics: Theory, Research, and Practice, 19(1), 45-61. doi:10.1037/gdn0000021 